\title{
Baoding Historical District Cityscape Planning
}

\author{
Guo Zhou, Hongwei Li \\ College of urban and rural construction, Agricultural University of Hebei, Baoding, RP. China. \\ zhouguo_359@163.com
}

Keywords: Cityscape, Natural resource, Historical culture, Specialty planning, Baoding city

Abstract. By integrating historical accumulation and outstanding natural landscape, cityscape planning could create impressive and easy-sensory city image. By means of natural situation, historical and cultural resources, Hebei Baoding historical district cityscape planning makes plan for landscape theme, landscape layout, urban space corridor, building height, skyline, open space, street construction public art and night view. These plans could offer references for other domestic cities.

\section{Introduction}

City's historical district is the source of the city's history and context, also the soul of urban construction. In the process of rapid urbanization, city's personality is gradually being diluted. The city's historical district was damaged in varied degrees in the process of urban renewal. Thus inheritance of culture and continuation of urban civilization is imperative.

\section{Urban landscape planning theory}

Urban landscape planning theory contains a lot of contents. Researchers generally believe that: Urban landscape is reflected on the city civilization and city life through the natural landscape and man-made landscape. One part of the urban landscape is social and human oriented software system, reflected on social customs and local conditions. The other part is city integrated hardware system, reflected on tangible form and intangible space. It is the carrier of the software system [1].

Urban landscape planning is based on exhaustive research. Through detailed analysis and integration of urban resources, the historical context, humanities and other elements of the city could be added into landscape planning. Thus distinctive planning system could be formed which can strengthen the qualities of the city and show the unique features and characteristics.

\section{Analysis of Baoding city's urban landscape}

\section{Geography and transport}

Baoding is located in the west-central portion of Hebei province and lies on the North China Plain, with the Taihang Mountains to the west. Baoding borders Beijing to the northeast and Shanxi to the west. Baoding has good connections to other cities, being located on one of the main routes in and out of Beijing [2].

\section{Natural landscape}

Baoding city has important green natural landscape, including the moat water system, the zoo, the Lotus Pond and so on. Affected by urban production and living, Baoding's natural environment are subject to different degrees of damage, such as moat water system contaminated, ancient trees lack of effective protection.

\section{Historical landscape}

(1) Old Town

Baoding is a city with a history dating back to the Western Han Dynasty. It was destroyed by the Mongols in the 13th century, but after the Mongols established the Yuan Dynasty, it was rebuilt. It acquired the name "Baoding" during the Yuan Dynasty. Baoding served for many years as the capital of Zhili, and was a significant centre of culture in the Ming Dynasty and early Qing Dynasty 
[3]. Baoding city pattern was formed in Ming Dynasty. Although many additions updated in Ming and Qing Dynasties, but the overall pattern of the city is not changed.

(2) Culture relic protection site

Baoding has five national key cultural relics protection units, seven provincial cultural relics protection units, 24 municipal cultural relics protection units. Most heritages located in the old town or around, including 22 in the inner town, 12 in the vicinity of the town, and the remaining two is in the central city.

There are two main types of heritages in Baoding City: ancient buildings and modern historical sites. There are 36 cultural relics protection units in downtown, 20 ancient buildings, 16 modern historical sites. Lotus Pond and Zhili Govern-general's Office are the representatives of the ancient buildings which witnessed the historical changes from Song to Qing Dynasty in Baoding. While Baoding military school site and Yude school site are the representatives of modern times which witnessed the development of Baoding modern culture.

(3) Traditional residence

In 1993, the Baoding City People's Government identified 11 key protected residences which are located in the historical district. Currently, 8 key protection residential sites are reserved and three were integral moved [4]. Except these 11 residences, some intact traditional residences are reserved in the mosque neighborhood and the memorial temple of Huai loyalty army area. These traditional residences are main components of traditional blocks which should be protected in the plan.

\section{Historic district cityscape planning}

\section{Cityscape theme}

Following Baoding's overall development orientation, "cultural city, landscape city, low-carbon city" was determined as the dominant direction for shaping historic district cityscape [4]. Based on the Ming and Qing architectural style, guided with "history, culture, heavy" as the theme, the historic district could show a warm gray cityscape image, like a Chinese ink painting, after repairing the essence of heritage and renewing old architecture.

\section{Cityscape structure}

The historic district contains the city moat zone and moat outside border, with a total area of $4.25 \mathrm{~km}^{2}$. Cityscape structure of the historic district could be described as: "One belt, two areas and five streets." as shown in Fig. 1. "One belt" means the ancient style belt; "two areas" means the Lotus Pond area and the memorial temple of Huai loyalty army area; "five streets" means the East Main Street, South Street, North Street, Temple Street and Yuhua Road [4].

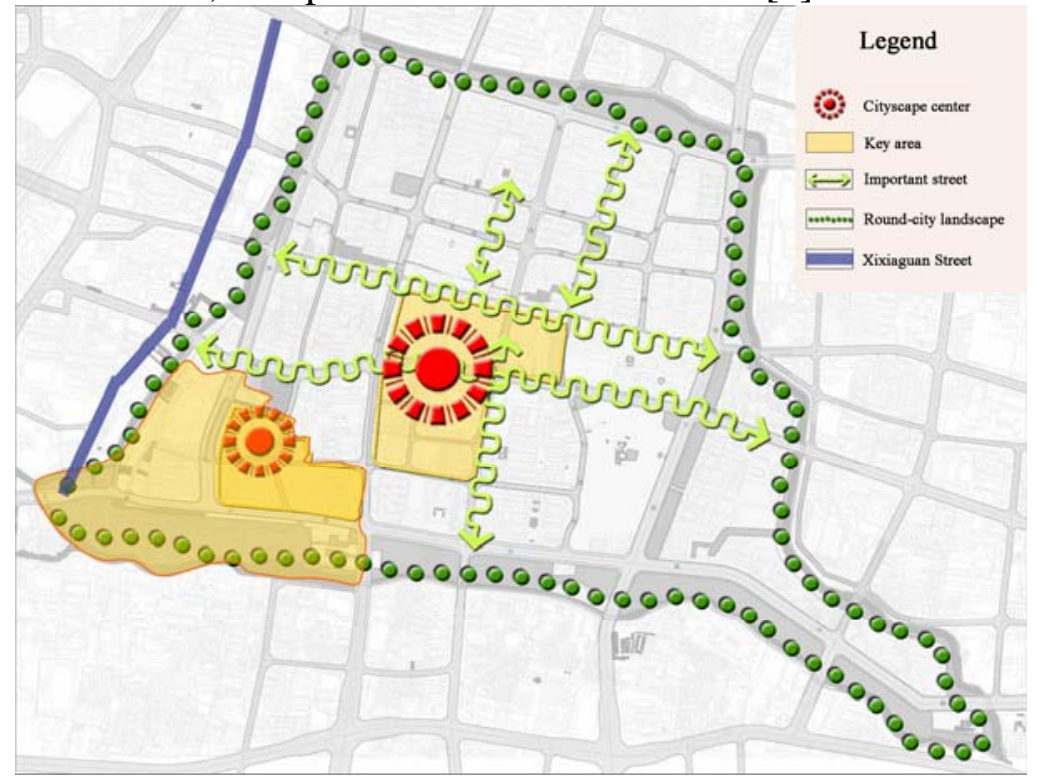

Fig.1. Baoding historical district cityscape structure. 


\section{Architectural style guide}

(1) Architecture color control

Architecture color reflects the regionalism, national identity and cultural traditions. It mainly reflects through the building's exterior materials, especially for roof and walls. From the view of the entire city, it can be divided into body colors and decorative colors. The color theme of the historical district in Baoding is "elegant rhyme." The color control principle is that elegant gray is the main color; the secondary colors are white, wood color red and brown as shown in Fig. 2. The proportion of decorative colors in the facade is less than $5 \%$, and most concentrates in the bottom of the building.

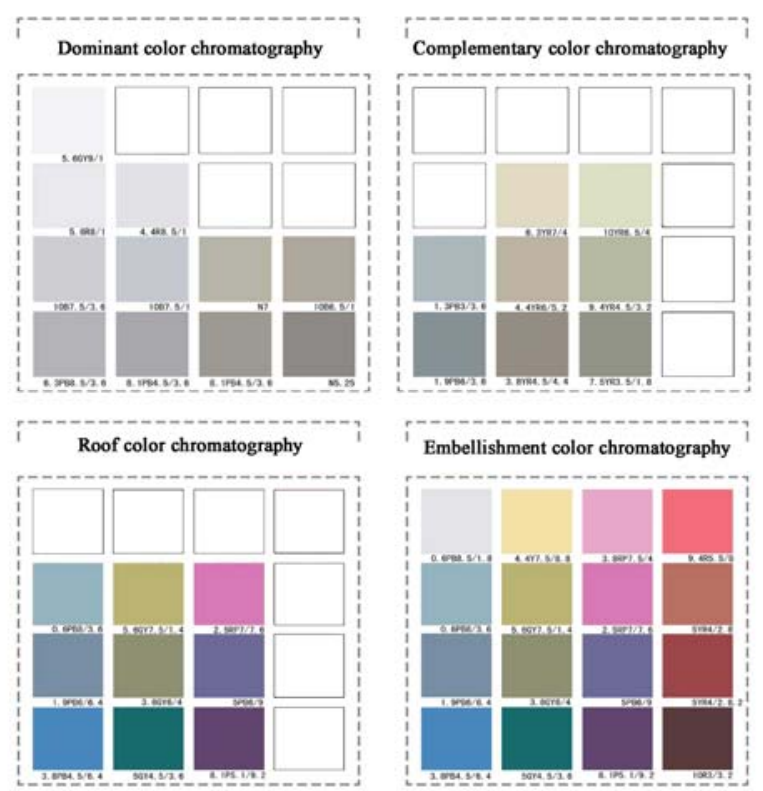

Fig.2. The architecture color theme of Baoding historical district.

(2) Architectural style control

The architectural style of these important historical buildings in the old town is dominated. The other modern architectures nearby or in the blocks should be in harmony with the historical buildings. It can be divided into four main styles. Traditional style building, like Daiji Court, Bell Tower, Lotus Pond, Governor Buildings, reflects in the architectural style of the Ming and Qing Dynasty; Chinese and Western style architectures (Republican period) mainly concentrate in the East Main Street and around the Catholic Church; ethnic style buildings are mainly around the mosque; the northern Hui architectural style is mainly in the memorial temple of Huai loyalty army area.

\section{Street construction}

Urban road landscape includes roads greening, building styles on sides, sidewalks pavement, bus stops, trash cans, chairs, mailboxes and so on. The city roads can be classified into traffic type, life type, landscape type, commercial type according to their features and styles. The road construction should be designed in the corresponding to their characteristics.

\section{Key area construction}

Historical district is partitioned managed and constructed. Every priority area is reformed and controlled detailedly, including Shengli Alley area, Chrysan Alley area, Governor - Lotus area and Qinghe Road area, as shown in Fig. 3. In the planning, after the transformation, all the buildings should be coordinated with the traditional architecture in height, facade, material, color, etc. While the architectural composition and style of historical buildings could be continued. 


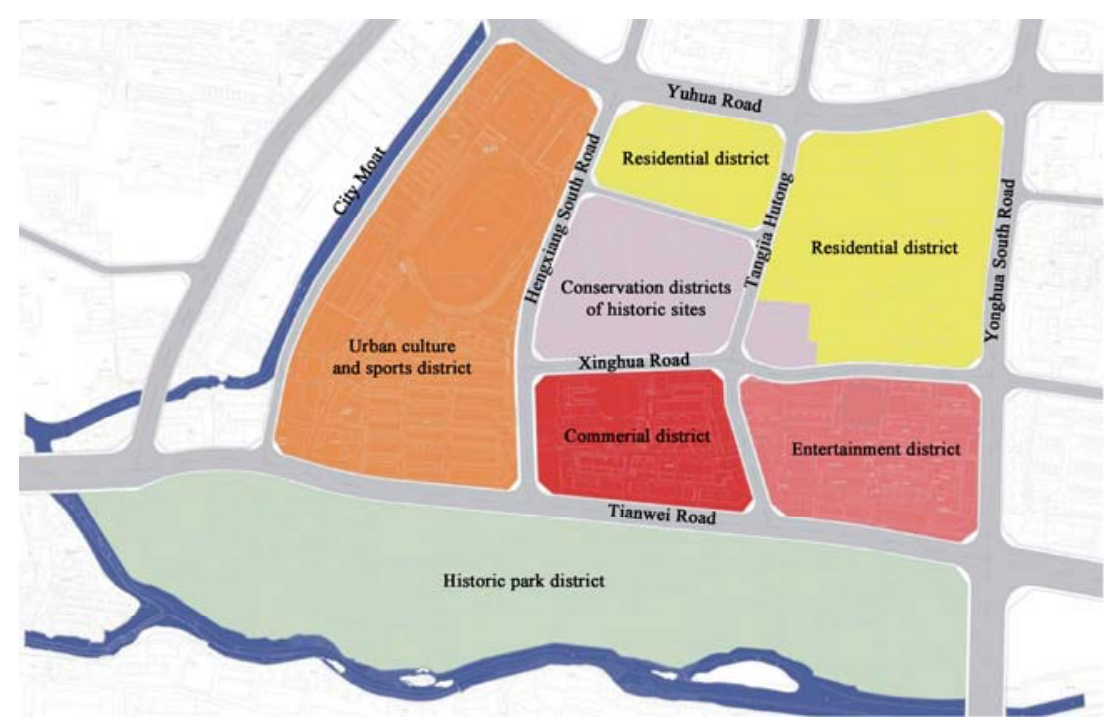

Fig.3. The key area construction of Baoding historical district.

\section{Open space}

In the new cityscape planning, the existing open space will be maintained; the new open space system will extend from the axis which begins from Governor Square to Daiji Court. One belt green landscape with 21 scenes will be constructed around the city moat water and riverside, as shown in Fig. 4.

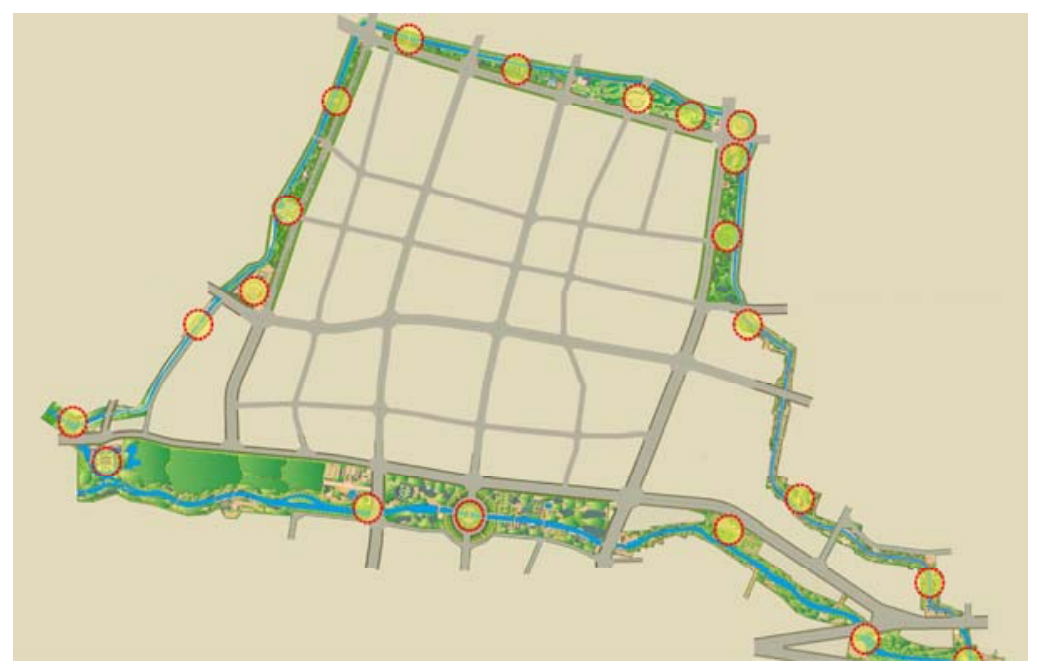

Fig.4. The planned open space of Baoding historical district.

\section{Public art}

Public art should inherit ancient culture and essence not only in terms of color, also in form and content. As to the sculpture, the themes should be close to public life and the history stories. For the hard pavement, local stone could be used as the materials. Using varying mosaic and inlay methods and combining with traditional style elements could make the old town classical. As to the street block facilities, road signs and street decorations should be added art elements in harmony with the historical district landscape.

\section{Skyline planning}

Skyline planning is to ensure the sight permeability of the city's iconic landscape and historic buildings. The height of modern buildings should be controlled to avoid blocking historical buildings and landscape sites.

\section{Night view planning}

Historical district is of the second high illuminance area and medium temperature area. It should be applied with light color. Based on the functional lighting, landscape lighting should be coordinated in light, color and style. Yellow light is recommend as the dominant, while colorful light should be as less as possible. Road lighting must meet the security intensity of illumination. The shapes of lamps 
should be coordinated with the overall style of historical district. Installation of landscape lighting must not destroy the original features and the outer surface area of buildings.

\section{Conclusion}

The key point of urban development has shifted from laying the framework of cities and development to perfecting citied functions, improvement of urban environment and improving urban life quality. In the rapid urban construction progress, making special cityscape planning is of great practical significance. It also provides a reference for other domestic cities.

\section{References}

[1] Ping Zhang, Yingjun Li, Hongjuan Zhang, Yufeng Zhao, Lina Yang: Planners. Vol. 29 (2013), p. 62-69. In Chinese.

[2] Information on https://en.wikipedia.org/wiki/Baoding.

[3] Information on http://www.showchina.org/tour/lyd/baoding/3/201005/t639507.htm . In Chinese.

[4] Baoding City urban scape short-term planning (2015). Urban and Rural Planning and Design Institute of Baoding City. In Chinese. 